\title{
Os sentidos midiáticos da ordem e da monstruosidade em Dexter
}

\author{
Danielle Ramos Brasiliense
}

\section{Resumo}

Neste artigo, abordamos a série televisiva Dexter, produzida desde 2006 pela empresa americana Show Time, para refletirmos sobre a construção do personagem principal, a partir da produção de sentidos estigmatizados em torno dos conceitos de ordem e monstruosidade que permeiam os ideais do senso comum. Na série, atualmente em sua quarta temporada, Dexter Morgan é um herói diferente, repleto de ambiguidades e contradições, e atua como um serial killer que mata serial killers. A partir desta abordagem inusitada no que tange aos programas do gênero, interessa-nos pensar a relação entre a construção dessa personagem, os valores classificatórios acerca do bem e do mal partilhados pelo senso comum e as formas de representação que eles assumem no universo da cultura midiática contemporânea.

Palavras-chave

Monstruosidade. Estereótipo. Ordem social. Mídia.

Danielle Ramos Brasiliense I dabrasiliense@gmail.com Universidade Federal do Rio de Janeiro. Professora na Universidade Federal Fluminense do curso de Comunicação Social. Doutoranda do Programa de Pós-Graduação da ECO-UFRJ, sob a orientação da profa . Dra . Ana Paula Goulart Ribeiro. É jornalista e mestre pelo Programa de Pós-Graduação em Comunicação da UFF.

\section{Introdução}

"Eu não sou o monstro que ele quer que eu seja.

Então não sou homem, nem animal. Sou algo inteiramente novo. Com minhas próprias regras. Sou Dexter."

Dexter, a série de TV lançada em julho de 2006, pela produtora americana Show Time, e transmitida atualmente pelo canal FX de TV fechada, vem gerando grande audiência, especialmente entre os fãs de filmes policiais que contam histórias de crimes provocados por serial killers. A série já teve quatro temporadas exibidas até 0 final do ano de 2009. Michael C. Hall é 0 ator principal que vive a personagem Dexter Morgan, um perito da polícia, especialista em sangue, que foi treinado por seu pai, Harry Morgan, para matar os assassinos mais cruéis da cidade de Miami, o que ele realiza através de um modus operandi característico de um serial killer. Trata-se, portanto, de um programa televisivo que tem como "herói" um serial killer que mata serial killers.

Esta série nos chamou atenção por conta dos estudos sobre monstruosidade e mídia, pontos 
fundamentais para 0 desenvolvimento da tese de doutorad $0^{1}$ sobre os discursos midiáticos e suas relações narrativas com os crimes de parricídio. A série Dexter, como indicamos acima, revela uma identidade monstruosa diferente, um monstro/ herói, um inocente/parricida. Dexter tem objetivo de limpar a cidade, manter a ordem e, por isso, usa seus instintos assassinos para matar indivíduos perigosos.

Sua tarefa é realizada sempre de maneira sistemática e compreende as seguintes etapas: surpreender suas vítimas com uma injeção anestésica no pescoço, amarrá-las com plásticos, imobilizá-las em uma cama improvisada e, logo depois de sacrificá-las, fatiar seus corpos. Esses atos não deixam de ser um ritual macabro de monstruosidade, mesmo que seu objetivo seja a limpeza de um mundo infectado por pessoas ruins. Não é por menos que Harry, pai de Dexter e 0 grande responsável pela construção e desenvolvimento da identidade monstruosa do filho, ao se deparar com a cena ritualística de morte criada por sua criatura, se suicida, pois percebe que seus objetivos de promover a ordem se tornam impossíveis sem a existência de uma desordem, como a monstruosidade. Assim, podemos observar que a vida da personagem Dexter é uma busca por entender o que pode ser considerado ordem e o que realmente pode ser denominado desordem, monstruosidade ou anormalidade.
A pesquisa de doutorado em andamento procura entender as questões que permeiam a construção de identidades monstruosas tipificadas, especialmente aquelas que se revelam no seio de uma das mais importantes instituições sociais, a família. Esse é o ponto fundamental que liga Dexter ao trabalho que está sendo produzido para a tese, pois a personagem principal é situada na trama por uma forte ligação com a instituição da família, lugar sinônimo de ordem. Mais que isso, Dexter marca esse lugar com a ambiguidade de uma identidade monstruosa e não-monstruosa ao mesmo tempo.

A série Dexter nos parece um produto de comunicação de massa importante a ser analisado, pois, com sua grande audiência, todos os sentidos ali apresentados estão se reconfigurando de alguma forma para os telespectadores. Então nos perguntamos: 0 que Dexter nos apresenta? Que sentidos esse programa produz em sua exibição? Como o senso comum, em meio a tamanha ambiguidade, é administrado? Como é apresentada de fato a identidade da personagem Dexter e que caminhos procura tomar?

Foram diversas as questões que despertaram 0 interesse por esta série. Em primeiro lugar, a questão do equilíbrio da monstruosidade dado pelos ideais de uma ordem cuja referência é a família. Dexter, o serial killer, é moldado pelo 
poder do pai, Harry, o policial que 0 adota e vira uma referência de vida equilibrada pela normalidade. Um dos mais importantes princípios impostos pelo personagem de Harry para a sobrevivência do filho Dexter é a família, referência e base, para que 0 monstro serial killer que vive dentro dele não seja despertado, a não ser em um caso de necessidade e emergência social. 0 pai, que só aparece nas lembranças de Dexter, o aconselha à beira da morte a se prender à sua irmã Debra como fonte de equilíbrio. Esta série deixa clara a ideia de família como pilar de sustentação de uma ordem.

As raízes da evolução da família como sentido de verdade e lugar da ordem social foram consolidadas nos últimos séculos, especialmente no período da Revolução Francesa, quando as discussões sobre o público e 0 privado foram decisivas para entender a evolução deste plano ideal que constitui o lar, o pai, a mãe e os filhos. E assim como a ideia de família não desapareceu da história do homem desde então, os crimes cometidos contra ela, como os de parricídio, continuam ocorrendo e sendo caracterizados como monstruosos em razão de levarem à quebra de um tabu. A morte de um pai causada pelo filho é a contradição mais espantosa em uma realidade social ajustada por ideais de ordem e que, por isso, tende a sublimar existências desordenadas. Desordens são sentidos contrários ao que se considera verdade.
0 tabu é o elemento demoníaco que não pode ser tocado, é algo intocável, proibido, misterioso, consagrado e perigoso. Nossas concepções de impureza pertencem ao campo do tabu. Segundo Freud, as mais antigas proibições estão ligadas às leis do totemismo, que são "não matar o animal totêmico" e "evitar relações sexuais com membros do mesmo totem" (FREUD, 2005). 0 tabu, então, é tudo o que um sistema social traduz como sagrado, proibido de ser tocado, ou alterado.

Para ampliar esta reflexão, podemos citar uma matéria do G1 notícias (10 fev. 2009), que informava acerca da exclusão do jovem Cyril Jaquet, de 29 anos, participante de um programa de reality show espanhol, depois que descobriuse que o rapaz, em 1994, com quinze anos, havia matado seus pais. Cyril declarou ao jornal que o entrevistou: "A mídia não deixa que esqueçam 0 seu passado, mas a gente muda [...]. Não quero dizer nada (sobre 0 acontecido), o passado está enterrado para mim" (HOMEM, 2009). Mesmo passado tanto tempo, e tendo cumprido pena de dois anos na época por ser menor, o rapaz é percebido como um exemplo de monstruosidade e, por isso, o público repudiou sua participação. Um parricida não é aceito como um bom exemplo para as famílias que iriam assistir ao programa, e isso levou a produtora do programa a excluí-lo do mesmo. Cyril Jaquet não pôde ficar exposto no reality show da TV por sua tipificação monstruosa como um criminoso sem referências de ordem. A partir desse caso, podemos nos perguntar como 
se adaptam essas questões de monstruosidade típica na série Dexter, exibida pela FX, já que o personagem principal é ao mesmo tempo um herói e um assassino em série?

Os casos de parricídios, assim como todo crime considerado bárbaro, ganham uma aproximação imediata com a categoria grotesca da monstruosidade, por serem crimes que ultrapassam o lugar do cotidiano, ou de certa "normalidade". Matar o próprio pai é quebrar uma conduta moral, é muito mais do que um assassinato, por isso se estabelece a monstruosidade dos sujeitos nesta realidade contraditória e complexa para o mundo que exalta a ordem social.

No caso de Dexter, a questão da família como reguladora da sua desordem é fundamental para pensar o crime de parricídio como aquele que quebra as regras construídas por estes ideais de organização do mundo sagrado e intocável. Ao saber que seu pai se suicida logo após ver de perto sua criatura em ação bizarra, Dexter reconhece ter matado seu pai. Mas isso não ocorre de fato, ele não enterra seu punhal no peito de Harry. Embora o personagem Dexter não seja diretamente um parricida, ele é um típico monstruoso moldado pelos ensinamentos do pai, cujo poder é soberano, e isso revela a força imaginária deste lugar sagrado que não pode ser de modo algum destruído. Burlar as ordens morais ensinadas por Harry seria a mesma coisa que cometer um parricídio.
Um crime de parricídio ou um assassinato em série só é considerado monstruoso por derrubar os ideais de ordem? Não. Esses crimes, além de chocarem a moral construída por tabus, despertam a ideia de proximidade de uma maldade que não só pode aparecer em qualquer ser humano, dentro da sua própria casa, mas também pode ser reconhecida dentro de cada um de nós. Todos nós temos, em tese, um Dexter que pode ser despertado para causar o horror, embora geralmente só se reconheça esse monstro no outro, naquilo que está fora de nós mesmos. E isso não é diferente para a personagem desta série, que, mesmo sendo um assassino sob justa causa, só se percebe como monstro na relação com a normalidade.

Mas como nos comportamos em um momento em que esse outro, que completa nossa vida e de quem nós dependemos para viver e promover sentido no mundo, se torna uma ameaça? 0 outro é, ao mesmo tempo, aquele que nos constitui, mas também é 0 outro temido por nós, pela falta de conhecimento que temos da sua totalidade. Como discursar, então, sobre esta causa que rompe com uma relação aparentemente harmoniosa de construção de sentidos entre o Eu e o Outro? Esse sem dúvida é mais um ponto fundamental a ser desenvolvido neste artigo.

\section{Dexter, o monstro criado como herói}

A série, de modo geral, reitera o lugar do pai como referência de ordem, de normalidade e verdade absoluta. A primeira temporada conta 
a história da personagem principal. Dexter é adotado por um policial aos três anos de idade, após ser encontrado dentro de um contêiner banhado pelo sangue de sua mãe, brutalmente morta e fatiada por uma serra elétrica. "Você foi deixado lá por dias, faminto e recheado de sangue"2, diz Camila, a arquivista do Departamento de polícia onde Dexter trabalha e onde seu pai Harry também atuou.

Harry Morgan, um policial experiente, percebe com o passar dos anos que seu novo filho tem obsessão por sangue e consequentemente fantasias sobre capturar presas e matá-las. 0 pai o julga como um nato serial killer e constrói uma forma de deter seus impulsos. Preocupado com o futuro de Dexter, Harry formula alguns códigos de conduta moral e ensina ao menino que matar uma pessoa não é apenas assassinála, mas privá-la de tudo que ela pode se tornar um dia, e, portanto, o jovem só deveria usar uma arma contra alguém se houvesse um objetivo de salvar a si mesmo ou a sociedade, pois, caso contrário, isso seria só um crime e ele se tornaria um assassino cujo futuro estaria restringido à prisão e à morte. Harry aproveita os desejos sanguinários de Dexter para formar um serial killer de serial killers, um monstro invisível na sociedade, cujo distúrbio interno é regulado por um código de normalidade, já que, para o policial experiente, 0 destino do filho não poderia ser mudado. Dexter é o herói com identidade secreta assim como o Super-Homem, ou o Homem-

Aranha, mas a contradição de bondade absoluta é o seu diferencial, pois Dexter é um monstro/ herói, um serial killer como suas vítimas, mesmo com intuito de ajudar a sociedade, eliminando pessoas com as mesmas características e instintos assassinos que os delas. 0 mistério de Dexter, diferente dos comuns super-heróis, é guardar dentro de si um monstro que só se revela em favor da sociedade. Geralmente o herói não é ao mesmo tempo um monstro, ao contrário, os enredos costumam colocar vilãos e heróis em lugares separados. Dexter é, portanto, uma novidade nesse sentido.

A série Dexter é um produto de comunicação de massa que propõe uma abordagem diferente. Não é uma série ou uma história como as outras, pois o lugar do herói é ambíguo.

Sem dúvida, os episódios são marcados por personagens estereotipados em produções americanas, como latinos na cidade de Miami, por exemplo. Mesmo sob essa condição, a série permite que os telespectadores tenham uma quebra do senso comum, pois os personagens tradicionais deste tipo de entretenimento fazem com que o contraditório Dexter se destaque significativamente. Parece-nos, então, um marco do olhar da diferença entre o senso comum e a percepção da contradição da realidade. Pensamos isso mediante a ideia de que o senso comum enquadra as realidades ambíguas que 
nos cercam: monstros são absolutamente maus, e heróis são completamente bons.

É interessante perceber que em Dexter os telespectadores não torcem por ele apenas por ele ser um justiceiro, mas por demonstrar toda a questão do cotidiano, pois, embora ele seja um assassino, ele é uma figura que demonstra 0 comum, com sua vida no trabalho, nas relações com a namorada, nos seus erros e trapalhadas.

0 que une Dexter com o telespectador são as situações de vivência do cotidiano e suas experiências com 0 acaso. Obviamente, a produção do seriado investe em enquadramentos de imagens, sons e narrativas que enfatizam mais a violência, o mistério ou os conflitos vividos pela sua ambiguidade.

As cenas musicadas produzidas para abertura dos episódios demonstram a ênfase nessa relação entre cotidiano e monstruosidade. Dexter desperta pela manhã com um mosquito que morde seu braço. Com um forte e certeiro tapa ele mata 0 inseto. Essas duas primeiras cenas marcam a precisão do personagem em eliminar quem o incomoda, mas, ao mesmo tempo, passam também a ideia de que é alguém que acorda sendo picado por um mosquito, algo absolutamente comum. Após levantar-se, ele se barbeia, seu rosto é cortado e o sangue pinga na pia. As cenas mostram sua relação com o sangue, mas, mesmo em procedimentos cotidianos e aparentemente normais, as imagens são carregadas de ambiguidade. Ele corta bifes, frita-os e os devora como um monstro carnívoro. Quebra um ovo e o come frito com catchup, que marca a presença da cor vermelha do sangue. Faz café na cafeteria, que tritura os grãos, corta uma fruta e a espreme para o suco, como se fizesse o mesmo trabalho com corpos de pessoas. Enrola o fio dental nos dedos e o passa nos dentes com intensidade, laça os sapatos e os amarra com força, põe a camisa, que cobre o seu rosto como máscara por lentos segundos. Ele fecha a porta do apartamento com a chave e sai com ar de felicidade e bom-humor pelo corredor do prédio. Sangue, cortes, amarras, mordida feroz, agressividade. Despertar do sono, barbear-se, tomar café da manhã, vestir-se e sair de casa. Essas cenas revelam o cotidiano comum da maioria americana, isso aproxima a personagem de seu público observador. Mas o que desperta a curiosidade são as dualidades que propõem essas filmagens, pois, ao mesmo tempo, mostram o cotidiano e a preparação de um típico serial killer com seus atos, gostos e vestimentas, um ser assustador, ou um homem solteiro comum, que acorda e se prepara para sair de casa.

0 enquadramento de Dexter na vida de normalidade se dá na sua relação com os companheiros de trabalho, onde ele é o camarada que distribui rosquinhas todos os dias pela manhã, e também na convivência com sua namorada Rita e seus filhos. Rita é uma mulher separada de um presidiário, pai de sua filha Astor e do caçula Cody. Uma mulher comum, trabalhadora, dona de casa e com ar contido, sem 
muitas vaidades. Dexter a considera a mulher ideal para ter um relacionamento, pois, assim como ele, não se interessa por grandes emoções e ambições na vida ordenada pela normalidade. Depois da morte do pai, Dexter se baseia nesta família e conta também com sua irmã Debra para não se desviar dos códigos e matar qualquer pessoa somente por prazer. Basta, então, seguir regras de condutas receitadas por Harry, para não se desviar do caminho do bem, pois, mesmo que viva cometendo crimes, 0 importante é que este mal não custe nunca a vida de inocentes.

Para diminuir os impulsos do garoto, o pai caçava animais, dava o primeiro tiro e deixava Dexter fatiar e escalpelar a presa. Em um dos flash-backs dos episódios Harry recomenda: "as pessoas normais não gostam de ficar sozinhas, você deve parecer normal." Toda a ideia de normalidade que Dexter possui, portanto, foi criada pelo personagem do seu pai, que é entendido como a referência, o poder maior, 0 exemplo a ser seguido.

É nesta base que Dexter vai crescer e aprender a se manter limpo. No livro 0 mal-estar $d a$ Pós-Modernidade, Zygmunt Baumann (1998) fala que as grandes ideias de crimes como os do Nazismo são baseadas em defender a harmonia estética e social. Pessoas que não se adéquam a determinado lugar, que representam ameaça, que poluem a estética harmônica e agradável de determinado espaço, devem ser excluídas, pois estão sob a condição de poluição. 0 autor, inclusive, lembra a "nau dos loucos" estudada por Foucault (2005), que demonstra na obra História da loucura a criação dessa divisão entre pureza e impureza. Os loucos passam a representar ameaça e a ser objeto de escárnio, sendo, portanto, seres da desordem social. São seres contraditórios à realidade harmônica, pois têm em seu caráter a mentira no lugar da verdade, a violência no lugar da justiça. A partir dessa lógica de pensamento é que se institui o monstruoso como aquele que é estrangeiro aos olhos da razão moral.

Embora seja um assassino, a personagem Dexter aprende a se manter aparentemente limpo, para não ser excluído da sociedade. As palavras de Bauman nos permitem refletir sobre a possibilidade de Dexter ter sido treinado a viver no mundo da ordem, mesmo tendo hábitos de desordem: "Nós humanos, somos dotados de memória e de uma capacidade de aprender; por esse motivo, conferimos benefício a uma boa organização do mundo. Habilidades aprendidas para a ação constituem poderosos bens num mundo estável e previsível" (BAUMAN, 1998, p. 16).

0 que Harry, com seu poder de pai, chama a atenção de Dexter nos momentos em que 0 ensina a ter um comportamento normal é que ele jamais deve se desviar ou surpreender o mundo com sua monstruosidade. Ele deve, assim, deixar seu lado impuro congelado, escondido, enquanto se relaciona com a sociedade que crê em padrões 
de pureza. Dexter vive uma vida de mentiras, superficial, um "garotinho de madeira", como ele mesmo diz na série, com corpo condenado a uma moldura, um engessamento.

Com a revelação de sua identidade monstruosa, não seria possível viver no mundo da normalidade. A chegada de um estranho, como mostra Bauman em seu livro, tem o impacto de um terremoto: "o estranho despedaça a rocha sobre a qual repousa a segurança da vida diária" (BAUMAN, 1998, p. 19). Sob este aspecto, podemos ligar a questão de quebra dos valores de família, no momento em que o monstro é identificado, pois tanto a descoberta de um serial killer, como a de um assassino dentro de casa, tem o mesmo efeito turbulento; a diferença é que o parricida é aquele que anula o centro, a referência maior dessa ordem que é o pai.

Segundo Mary Douglas, em Pureza e perigo, impureza é uma ofensa contra a ordem e quando a eliminamos estamos nos esforçando para organizar o nosso meio. A cultura midiática, assim como qualquer outra cultura, tem sistemas de classificação que interagem com nossos hábitos mentais enraizados pela própria experiência cultural. "Poderia pensar-se que, numa cultura profundamente impregnada de noções de contágio e de purificação, o indivíduo se encontra oprimido por categorias rígidas e pensamentos cuja manutenção depende do auxílio de punições e de regras de evitamento" (DOUGLAS, 1991, p. 18).
Mary Douglas diz que é possível criar uma nova ordem na qual a anomalia possa ser absorvida, mas existe uma questão de poder cultural, que vem da autoridade da fala pública sobre essa ordem. Estas categorias classificatórias que fazem parte do universo do senso comum são assuntos públicos e, por isso, tão difíceis de ser repensadas. Não são postos em questão e, com isso, não se constroem hipóteses com relação aos acontecimentos que permitam a quebra da ideia de ordem. Douglas fala que, mesmo sob a vivência de receitas, qualquer cultura ou sistema classificatório pré-determinado pode sofrer alterações com acontecimentos que produzam anomalias e desequilibrem essas ideias.

\section{Dexter, uma personagem em contradição}

Se, como vimos acima, a primeira temporada narrou a formação de Dexter como serial killer a partir de um código normativo criado por seu pai, a segunda temporada mostra os conflitos de Dexter com relação a esse mesmo código, no qual essa vida ordenada e de normalidade é a ideal a ser seguida. Ele se vê diante de um grande risco de falhar com a primeira das regras ensinadas por Harry: "nunca ser pego", quando suas vítimas fatiadas são encontradas no fundo do mar. A imprensa denomina o causador dessas mortes " 0 açougueiro de Bay Harbor".

Em meio à tensão de ser descoberto como 0 grande assassino, Dexter conhece uma mulher chamada Lila, com quem ele descobre a 
ambiguidade de sua mascarada monstruosidade. Lila é o símbolo da contradição, que Dexter não foi acostumado a reconhecer como realidade possível, pois seu pai o ensinou a encarnar um personagem de normalidade absoluta, que vive sob a guarda do senso comum, no qual, inclusive, se encaixam as justificativas dos seus momentos de anormalidade criminosa, deixando assim, por causa justa, de ser percebido como ser contraditório, como vimos anteriormente. Lila, neste sentido, é a antítese de Rita, sua namorada desde a primeira temporada, que simboliza 0 mundo cotidiano e normatizador da família.

0 conflito com a ordem começa quando Dexter descobre uma mentira de seu pai a respeito da morte de sua mãe biológica, Laura Mosser. A mãe da personagem principal teria sido informante e amante de Harry Morgan. Ela entregou ao policial um esquema de tráfico de drogas e com isso acabou morrendo por um descuido de Morgan. 0 policial enterra os arquivos que provam a morte de sua informante, a mãe de Dexter, não para proteger seu filho adotivo, mas para poupar a si mesmo de ser reconhecido como um homem covarde que indiretamente é responsável pela morte da mãe do rapaz. Após escutar os áudios que revelam essa realidade, Dexter tem a primeira decepção com seu pai, o criador do código de conduta da sua vida: "construí minha vida pelo código de Harry, vivia por ele. Mas Harry mentiu. Por que ele fez isso? 0 que mais desconheço? Minha fundação de concreto está se transformando em areia movediça."
Diante dessa situação, Dexter passa a não saber mais quem é. Lila aposta em convencê-lo de que não existe normalidade absoluta e diz: "somos todos bons, Dexter, e somos todos maus". Ele diz a Lila que sua sensibilidade com relação às pessoas começa a fazer efeito dentro dele, coisa que antes não acontecia, e isso o preocupa, pois, como havia aprendido, um monstro não deveria ter sentimentos. E então umflash-back mostra a cena de diálogo entre Dexter e seu pai, após uma consulta médica: "eu fingi ser outra pessoa”, diz Dexter. E seu pai responde: "o médico não viu o monstro que há em você. Continue assim." E então, depois dessa cena de memória, Dexter conclui: "isso foi no que ele me transformou."

Numa cena de crime em que chega para fazer a perícia sanguínea das vítimas assassinadas, Dexter se depara com um pôster de um desenho de um homem encapuzado sob o título "O Defensor Sombrio". Trata-se de um personagem serial killer que, com sua espada de vingança, transforma o errado em certo. Em frente a este pôster, Dexter tem um momento de reflexão sobre sua conduta de vida: "Eu sou o Açougueiro de Bay Harbor ou sou o corajoso Defensor Sombrio? Isso só o tempo pode dizer. 0 engraçado é que conheci alguém que não liga para o que sou". A personagem demonstra claramente aqui sua confusão interior, mas se sente aliviada ou ainda mais confusa por encontrar Lila, que não se sente incomodada em namorar um monstro. 
Essa mesma sensação de não estar sozinho no mundo acontece também na terceira temporada, quando Dexter faz amizade com Miguel Prado, um cubano defensor público da cidade, após ter assassinado sem querer seu irmão 0scar Prado. Dexter não tem amigos além daqueles com quem ele se relaciona no trabalho e joga boliche semanalmente, o St. Batista e Masuka. Assim, Lila e Miguel se tornam uma novidade, por terem disposição em se aproximar dele com afeto. Dexter descobre nos dois o caráter da monstruosidade. Saber que existem pessoas iguais a ele, com vidas normais, mas no fundo criminosas, perturba a personagem e a deixa ainda mais confusa com relação a sua crença na ordem como o melhor para a sociedade.

Com o aparecimento de Miguel em sua vida, Dexter passa a ignorar as mensagens de Harry, com quem está magoado. Existe, então, uma substituição do lugar de autoridade do pai para 0 lugar de autoridade de Miguel, um representante da lei que faz sucesso na cidade de Miami. Este personagem, muito cobrado na infância por seu pai, tem também sede de matar, mas por seu próprio bem; como por exemplo, eliminar pessoas que atrapalham sua carreira.

De acordo com Mikhail Bakhtin (BAKHTIN, 2003), em sua obra Estética da criação verbal, o ser não se basta, pois precisa da existência do outro para completar sua visão sobre o mundo. Antes de conhecer Lila ou Miguel, a referência do "outro" para Dexter era seu pai, sua irmã,
Rita, as crianças, os companheiros de trabalho e toda a normalidade que os constitui. A partir do momento em que o "eu" de Dexter entra em tensão com o "outro", representado por Lila e Miguel, que são, de certa forma, o mesmo que ele, seus pensamentos se confundem com relação aos valores que ele acreditava ser verdade.

Lila, a personagem que Dexter desejava sexualmente com intensidade e também com quem ele pôde compartilhar suas verdades mais sombrias, era uma assassina que matava suas vítimas queimadas ao provocar incêndios. Mas, antes de Dexter descobrir suas características desviantes, ele constrói uma relação intensa com Lila e se separa de Rita. Em questionamento sobre sua antiga relação, Dexter diz a Lila: "Rita e as crianças eram a única coisa que me mantinha como humano por um tempo". E Lila responde: "Eles estavam te mantendo humano, ou eram eles que estavam te fazendo se sentir como monstro?". Essa conversa com Lila faz Dexter pensar que a melhor coisa na vida é poder viver sem máscaras com uma pessoa que 0 apoia e acaba lhe mostrando as contradições da vida. Logo após estar sentindo o efeito dessa aparente liberdade de viver o que realmente é, Dexter é abordado por um telefonema do filho de Rita que o convida para assisti-lo numa apresentação da escola. Enquanto Dexter 0 assiste ao lado de Rita e da filha, ele pensa: "estou um pouco confuso, Lila é quem me mostra como tomar o controle. Parar de matar, ter uma vida limpa." Mas ao lado de Rita e das crianças é o momento em que ele diz se sentir definitivamente limpo. 
Até que um dia ele descobre o lado sombrio de Lila e compreende que a monstruosidade não pode ser vivida naturalmente, deve sempre ser encapada por uma normalidade aparente. Lila, diferentemente de Rita, era uma mulher que vivia no mundo da desordem, mas que não matava apenas por justiça; ao contrário, eliminava também pessoas inocentes. Isso para Dexter é imperdoável. Ele prefere a ordem, 0 mundo ideal. E, assim, ele tenta voltar para a vida de Rita e sua família, pois a sensação de limpeza tem a ver com o senso comum. Mesmo com toda a decepção com seu pai e após ter conhecido Lila e Miguel, a personagem de Dexter retorna aos seus conceitos enraizados e escolhe viver sob os ensinamentos da ordem ditados um dia como receita por Harry. Aqui fica clara a verdade do pai como ideal, ao conceito de pureza e normalidade como fortes anuladores de uma possível contradição.

Um conto do Rubem Fonseca chamado Belinha ilustra essa questão contraditória sobre ordem e desordem. Ele conta a história de uma jovem de classe média que namora um matador de aluguel, a quem ela encomenda a vida de seu próprio pai. 0 romancista cria uma realidade que revela o poder do lugar do pai na moral humana. A personagem do assassino profissional se sente incomodada com o pedido da namorada e pessoalmente ofendida com a situação de ter ao seu lado uma pessoa com desejos parricidas: "Quero que você mate meu pai. Fiquei calado. Matar o pai, pensei, porra, a gente pode matar todo mundo, menos o pai e a mãe da gente"

(FONSECA, 2006, p. 21). 0 bandido não conformado mata Belinha, pois reconhece nela um monstro mais monstruoso do que ele, e por isso era melhor que a matasse, evitando um crime de parricídio. É clara a forma de raciocínio do criminoso que, mesmo com todo seu trabalho no campo da desordem, no momento que se depara com o pedido da moça, resolve acabar com sua paixão para não se comprometer com a quebra de um tabu. Assim como Dexter, que, ao se deparar com a anormalidade de Lila, volta-se para 0 lugar ideal da normalidade, mesmo com toda sua prática de serial killer.

Podemos falar do conceito de exotopia para explicar essa relação da personagem criminosa com o seu outro. A exotopia diz respeito ao ponto de vista externo que faz com que consigamos enxergar o interno. A escolha de Dexter, assim como a do personagem de Rubem Fonseca, é a de enxergar a família para construir seu mundo normal. Sobre essa relação imprescindível com o outro que 0 faz permanecer no lugar de sujeito normal, o trecho abaixo de Bakhtin nos é útil para completar esse sentido: "a possibilidade de afirmação volitivo-emocional da minha imagem a partir do outro e para o outro: porque dentro de mim mesmo existe apenas a minha autoafirmação interna" (BAKHTIN, 2003, p. 28). A afirmação da monstruosidade de Dexter separada da sua auto-sensação interna se contrapõe ao vazio de raciocínio lógico por 
conta da existência da crença numa verdade chamada normalidade.

Dexter é um produto da diferença, não é uma série ou uma história como as outras já exibidas na TV a respeito de assassinos, ou serial killers. Dexter é a imagem da ambiguidade e da realidade contraditória. Trata-se da exibição de uma identidade contraditória e não totalmente cristalizada como se costuma fazer em programas massificados pela mídia.

Para pensar as identidades tipificadas como monstruosas, é importante entender as representações como um processo cultural pelo qual estabelecemos sentidos em nossas experiências. As práticas de significação são baseadas nessas representações que constroem as identidades, tanto individuais, quanto coletivas. Esse sistema de representação é apresentado pelos discursos, que posicionam os sujeitos e suas falas.

Interessa-nos, aqui, pensar a diferença como essência da identidade, que a partir da representação é marcada pela exclusão. Kathryn Woodward fala sobre sistemas classificatórios que demarcam o lugar da diferença. Citando Durkheim, a autora se apoia na ideia de que 0 sistema classificatório gera ordem à vida social e produz os significados por afirmações discursivas e por rituais (WOODWARD apud SILVA, 2000).

Mas também é importante pensar as identidades como um fluxo em constante mudança e não como elementos fixos e inertes, ou seja, essencialmente sagradas ou profanas. Assim como Heráclito pensou a pluralidade e mutabilidade do mundo e no devir a partir de choques de realidades contrárias que causavam harmonia, não há possibilidade de pensar em algo especificamente sagrado ou naturalmente profano, pois as realidades são contraditórias e fluidas. A essência de uma identidade não existe, 0 que há é o simbólico $\mathrm{e}$ a representação sobre esta.

As concepções de Durkheim (1970) acerca da relação entre autoridade moral e consciência coletiva podem ser tomadas para pensarmos a atuação da mídia, que, ao produzir sentidos através de práticas rituais, estimula os valores uma vez classificados pela sociedade. Ou seja, a mídia utiliza-se de sistemas classificatórios observados na cultura para dar sentido e construir representações do mundo social. Woodward (2000) diz que, entre os membros de uma sociedade, há um consenso sobre como classificar as coisas para manter a ordem social. Neste sentido, entendemos que a mídia ajuda na padronização e naturalização dos valores determinados pela cultura e organiza, assim, os sentidos, separando o puro do impuro e o que pertence à ordem do que não pertence.

\section{Conclusões preliminares}

Para concluir, podemos propor uma comparação simples entre Dexter e um programa do canal Discovery Chanel chamado $O$ indice da maldade 
(Most Devil), que mostra como o psiquiatra

Michael Stone classifica assassinos, a maioria acusada de cometer crimes contra família, em uma escala de maldade que contém vinte e dois itens. Os critérios para alocar determinado crime em um item ou outro são estipulados pelo especialista a partir de valores do senso comum. No nível dez, por exemplo, é enquadrado o caso de Susan Smith, que matou os dois filhos afogados ao empurrar o carro rio abaixo com as crianças trancadas dentro. Segundo o Dr. Stone, esse nível diz respeito aos assassinos egocêntricos de pessoas que são "pedras no caminho". De acordo com a história, os filhos eram um obstáculo na vida de Susan. Mas o caso de maior gravidade é 0 que se encaixa no último item, de número vinte e dois. É a história de Thereza Nore, que teve a infância perturbada, matou o primeiro marido, uma filha por inveja de sua elegância e outra filha trancada no armário sem alimentação. Esse caso não é mais grave pela quantidade de mortos, mas sim por Thereza ter feito tortura prolongada de suas vítimas, segundo o psiquiatra.

Esse programa do Discovery, ao contrário da série Dexter, classifica claramente a monstruosidade dos sujeitos sem demonstrar pontos que as contradizem. Stone formulou vinte e duas maneiras de enquadrar as identidades criminosas. Essa tipificação apresentada pelo programa de TV demonstra não apenas receitas de classificação dadas por um psiquiatra, mas dos significados e crenças de uma sociedade que se baseia na ordem.
0 programa do Discovery apresentado pelo Dr. Stone nos lembra o poder dos discursos psiquiátricos da década de 50 (século XX), de que fala Michel Foucault em sua obra $O s$ anormais. 0s médicos tinham, de certa forma, autoridade para condenar um criminoso ao relatar seus comportamentos. Foucault classifica tais discursos como grotescos pelo fato de serem criados por pessoas desqualificadas que detinham efeitos de poder (FOUCAULT,2001 p. 16). Para ele, os discursos sobre os criminosos eram "enunciados que possuem o estatuto de discursos verdadeiros, que detêm efeitos judiciários consideráveis e que têm, no entanto, a curiosa propriedade de ser alheios a todas as regras, mesmo as mais elementares de formação de um discurso científico [...]" (FOUCAULT, 2001, p. 14). Esta observação de Foucault nos remete ao pensamento sobre os produtores de cultura midiática e sua relação com os discursos providenciados pelas noções do senso comum sobre sujeitos identificados como criminosos na sociedade contemporânea.

Ao analisar os relatos dos peritos, Foucault percebe que seus valores são princípios para descrever o criminoso e para criar hipóteses sobre as realidades dos crimes cometidos. Esses profissionais demonstram ter pensamentos naturalizados pelo senso comum e pelas noções de tabu existentes na história social. Os raciocínios não se baseiam nas realidades contraditórias, mas, como relata Foucault, o pensamento se valida de uma falsa objetividade 
em que os psiquiatras declaram: "nós como peritos, não temos de dizer se ele cometeu 0 crime que lhe imputamos. Mas suponhamos que ele tenha cometido" (FOUCAULT, 2001, p. 21). A partir disso, criam-se hipóteses a respeito dos acusados e geralmente as narrativas são sobre sujeitos que ocupam o lugar da desordem, da impureza. São indivíduos que quebraram algum tipo de tabu e, portanto, precisam ser separados.

Embora Dexter seja uma série que proponha a diferença com relação à personagem heroica que é ao mesmo tempo um retrato da monstruosidade, a sua produção não hesita em mostrar que a ordem é o lugar ideal para se viver bem. Por isso, Dexter escolhe viver em família, principalmente no fim da terceira temporada quando ele descobre que vai ser pai. Ou seja, não importa a relação que o personagem principal de uma série tenha com o heroísmo ou monstruosidade, seu propósito de vida sempre será o da normalidade, ainda que esta seja apenas uma aparência.

Dexter é inovador no sentido de que o programa de TV mostra a contradição de um personagem e, ao mesmo tempo, a sua escolha de viver segundo a ordem familiar, lugar de proteção e guarda de todo o mal. 0 final da terceira temporada mostra a preocupação de Dexter com seu filho que Rita irá conceber. Ele se casa e decide que vai criar a criança ao lado de Rita. Assim, a personagem principal se mostra entusiasmada em dar uma boa educação ao filho e viver bem em família, mesmo com medo de que a criança se torne um serial killer como o pai. Mas, ainda assim, Dexter acredita na família e na posição do pai como referências da ordem social.

\section{Referências}

BAKHTIN, Michael. Estética da criação verbal.

São Paulo: Martins Fontes, 2003.

BAUMANN, Zygmunt. 0 mal-estar da Pós-

Modernidade. Rio de Janeiro: Jorge Zahar, 1998.

DOUGLAS, Mary. Pureza e perigo. Portugal:

Edições 70, 1991.

DURKHEIM, Émile. Sociologia e Filosofia. Rio de Janeiro: Forense-Universitária, 1970.

\section{As formas elementares da vida}

religiosa. São Paulo: Martins Fontes, 1996.

FONSECA, Rubem. Belinha. In: . Ela e outras mulheres. São Paulo: Companhia das Letras, 2006. p. 33 - 45.

FOUCAULT, Michel. História da loucura. São Paulo: Perspectiva, 2005.

Os anormais. São Paulo: Martins

Fontes, 2001.

FREUD, Sigmund. Totem e Tabu. Rio de Janeiro: Imago, 2005.

HOMEM condenado por matar os pais abandona reality show na Espanha. G1 notícias, Rio de Janeiro, 10 fev. 2009. Disponível em: <http:// g1.globo.com/Noticias/Mundo/0,,MUL9951115602,00-HOMEM+CONDENAD0+POR+MATAR+ 
OS+PAIS+ABANDONA+REALITY+SHOW+NA+E

SPANHA.html>. Acesso em: 26 jan. 2009.

PERROT, Michelle. Figuras e papéis. In:

(org.). História da Vida Privada 4: da Revolução

Francesa à Primeira Guerra. São Paulo:

Companhia das Letras, 1991.

ROSENFIELD, Denis L. Retratos do mal Rio de Janeiro: Jorge Zahar, 2003.

WOODWARD, Kathryn. Identidade e diferença: uma introdução teórica e conceitual. In: SILVA, Tomaz Tadeu da (org.); HALL, Stuart;

Identidade e diferença: a perspectiva dos estudos culturais. Petrópolis: Vozes, 2000. 


\section{The media senses of social} order and monstrosity in Dexter

\section{Abstract}

This paper discusses the TV series Dexter, produced since 2006 by the American company Show Time, to reflect on the construction of the main character, from the production of stigmatized meanings around the concepts of order and monstrosity that permeate common sense ideas. In the series, now in its fourth season, Dexter Morgan is a different hero, full of ambiguities and contradictions, acting as a serial killer who kills serial killers. From this unusual approach when it comes to programs gender, we are interested in thinking about the relationship between the construction of this character, the good and evil classification values shared by common sense and the forms of representation that they take in the world of contemporary media culture.

\section{Keywords}

Dexter. Monstrosity. Stereotype. Social Order. Media.

\section{Los sentidos mediáticos de orden y monstruosidad en Dexter}

\section{Resumen}

Este documento analiza la serie de televisión Dexter, producidos a partir de 2006 por el tiempo de la compañía estadounidense muestran a reflexionar sobre la construcción del personaje principal, desde la producción de sentido estigmatizadas en torno a los conceptos de orden y esa monstruosidad impregnar los ideales de sentido común. En la serie, ahora en su cuarto temporada, Dexter Morgan es un héroe diferente, llena de ambigüedades y contradicciones, actuando como un asesino en serie que mata a los asesinos en serie. Desde este enfoque inusual cuando se trata de programas de género, estamos interesados en la reflexión sobre la relación entre la construcción de este los valores de clasificación de caracteres sobre el bien y el mal compartida por el sentido común y las formas de representación que se tener en el mundo de la cultura mediática contemporánea.

\section{Palabras clave}

Dexter. Monstruosidad. Estereotipo. Orden social.

Medios de comunicación. 


\section{Expediente}

A revista E-Compós é a publicação científica em formato eletrônico da Associação Nacional dos Programas de Pós-Graduação em Comunicação (Compós). Lançada em 2004, tem como principal finalidade difundir a produção acadêmica de pesquisadores da área de Comunicação, inseridos em instituições do Brasil e do exterior.
E-COMPÓS I www.e-compos.org.br I E-ISSN 1808-2599

Revista da Associação Nacional dos Programas de Pós-Graduação em Comunicação. Brasília, v.12, n.3, set./dez. 2009.

A identificação das edições, a partir de 2008 passa a ser volume anual com três números.

\section{CONSELHO EDITORIAL}

Afonso Albuquerque

Universidade Federal Fluminense, Brasil

Alberto Carlos Augusto Klein

Universidade Estadual de Londrina, Brasi

Alex Fernando Teixeira Primo

Universidade Federal do Rio Grande do Sul, Brasil

Alfredo Vizeu

Universidade Federal de Pernambuco, Brasi

Ana Carolina Damboriarena Escosteguy

Pontifícia Universidade Católica do Rio Grande do Sul, Brasil

Ana Silvia Lopes Davi Médola

Universidade Estadual Paulista, Brasil

André Luiz Martins Lemos

Universidade Federal da Bahia, Brasil

Ângela Freire Prysthon

Universidade Federal de Pernambuco, Brasil

Antônio Fausto Neto

Universidade do Vale do Rio dos Sinos, Brasil

Antonio Carlos Hohlfeldt

Pontifícia Universidade Católica do Rio Grande do Sul, Brasil

Arlindo Ribeiro Machado

Universidade de São Paulo, Brasil

César Geraldo Guimarães

Universidade Federal de Minas Gerais, Brasi

Cristiane Freitas Gutfreind

Pontifícia Universidade Católica do Rio Grande do Sul, Brasil

Denilson Lopes

Universidade Federal do Rio de Janeiro, Brasil

Eduardo Peñuela Cañizal

Universidade Paulista, Brasil

Erick Felinto de Oliveira

Universidade do Estado do Rio de Janeiro, Brasil

Francisco Menezes Martins

Universidade Tuiuti do Paraná, Brasil

Gelson Santana

Universidade Anhembi/Morumbi, Brasil

Goiamérico Felício

Universidade Federal de Goiás, Brasil

Hector Ospina

Universidad de Manizales, Colômbia

Herom Vargas

Universidade Municipal de São Caetano do Sul, Brasil

leda Tucherman

Universidade Federal do Rio de Janeiro, Brasil

Itania Maria Mota Gomes

Universidade Federal da Bahia, Brasil

Janice Caiafa

Universidade Federal do Rio de Janeiro, Brasil

Jeder Silveira Janotti Junior

Universidade Federal da Bahia, Brasil

\section{João Freire Filho}

Universidade Federal do Rio de Janeiro, Brasil

John DH Downing

University of Texas at Austin, Estados Unidos

José Luiz Aidar Prado

Pontifícia Universidade Católica de São Paulo, Brasil

José Luiz Warren Jardim Gomes Braga

Universidade do Vale do Rio dos Sinos, Brasi

Juremir Machado da Silva

Pontifícia Universidade Católica do Rio Grande do Sul, Brasil

Lorraine Leu

University of Bristol, Grã-Bretanha

Luiz Claudio Martino

Universidade de Brasília, Brasil

Maria Immacolata Vassallo de Lopes

Universidade de São Paulo, Brasil

Maria Lucia Santaella

Pontifícia Universidade Católica de São Paulo, Brasil

Mauro Pereira Porto

Tulane University, Estados Unidos

Muniz Sodre de Araujo Cabral

Universidade Federal do Rio de Janeiro, Brasil

Nilda Aparecida Jacks

Universidade Federal do Rio Grande do Sul, Brasil

Paulo Roberto Gibaldi Vaz

Universidade Federal do Rio de Janeiro, Brasil

Renato Cordeiro Gomes

Pontifícia Universidade Católica do Rio de Janeiro, Brasil

Ronaldo George Helal

Universidade do Estado do Rio de Janeiro, Brasil

Rosana de Lima Soares

Universidade de São Paulo, Brasil

Rossana Reguillo

Instituto Tecnológico y de Estudios Superiores do Occidente, México

Rousiley Celi Moreira Maia

Universidade Federal de Minas Gerais, Brasil

Samuel Paiva

Universidade Federal de São Carlos, Brasil

Sebastião Albano

Universidade Federal do Rio Grande do Norte, Brasil

Sebastião Carlos de Morais Squirra

Universidade Metodista de São Paulo, Brasil

Simone Maria Andrade Pereira de Sá

Universidade Federal Fluminense, Brasi

Suzete Venturelli

Universidade de Brasília, Brasil

Valério Cruz Brittos

Universidade do Vale do Rio dos Sinos, Brasil

Veneza Mayora Ronsini

Universidade Federal de Santa Maria, Brasil

Vera Regina Veiga França

Universidade Federal de Minas Gerais, Brasi

\section{COMISSÃO EDITORIAL}

Felipe da Costa Trotta I Universidade Federal de Pernambuco, Brasil Rose Melo Rocha I Escola Superior de Propaganda e Marketing, Brasil

\section{CONSULTORES AD HOC}

Arthur Autran Franco de Sá Neto I Universidade Federal de São Carlos

Carlos Eduardo Franciscato I Universidade Federal de Sergipe

Elisa Reinhardt Piedras I Universidade Federal do Rio Grande do Su

Elizabeth Bastos Duarte I Universidade Federal de Santa Maria

Marcia Benetti Machado I Universidade Federal do Rio Grande do Sul

Sandra Maria Lúcia Pereira Gonçalves I Universidade Federal do Rio Grande do Sul

Suzana Kilpp I Universidade do Vale do Rio dos Sinos

Tattiana Gonçalves Teixeira I Universidade Federal de Santa Catarina

Vander Casaqui I Escola Superior de Propaganda e Marketing

Vicente Gosciola I Universidade Anhembi Morumbi

Walter Teixeira Lima Junior I Fundação Cásper Líbero

REVISÃO DE TEXTO E TRADUÇÃO I Everton Cardoso

EDITORAÇ̃̃ ELETRÔNICA I Raquel Castedo
COMPóS I www.compos.org.br

Associação Nacional dos Programas de Pós-Graduação em Comunicação

Presidente

Itania Maria Mota Gomes

Universidade Federal da Bahia, Brasil

itania@ufba.br

Vice-presidente

Julio Pinto

Pontifícia Universidade Católica de Minas Gerais, Brasil

juliopinto@pucminas.br

Secretária-Geral

Ana Carolina Escosteguy

Pontifícia Universidade Católica do Rio Grande do Sul, Brasil

carolad@pucrs.br 